\title{
Quantitative Research on the Scale and Benefit of Higher Vocational Education Under the Background of Competitive Funding
}

\author{
Yong Ding ${ }^{1, a}$ \\ ${ }^{I}$ Department of Public Courses, Hubei Communications Technical College, Hongshan, Wuhan, Hubei, China \\ a439676566@qq.com
}

\begin{abstract}
This paper analyzes and classifies the basic budget data of higher vocational colleges, studies the relationship between the scale and benefit of Higher Vocational Education under the background of competitive funding, establishes a linear programming model to maximize the benefit of running a school, conducts data simulation test, and obtains the benefits under different school scales, which can be used as a reference for the scientific management of higher vocational colleges.
\end{abstract}

Keywords: Competitive funding, higher vocational education, school scale, efficiency, quantitative research, mathematical model

\section{竞争性拨款背景下高职办学规模与效益的定量研究 \\ 丁勇 ${ }^{1, a}$}

${ }^{1}$ 湖北交通职业技术学院公共课部, 洪山, 武汉, 湖北, 中国

a439676566@qq.com

\section{摘要}

本文通过对高职院校预算基础数据进行分析归类，研究了竞争性拨款背景下高职办学规模与效益的关 系, 建立了办学效益最大化的线性规划模型, 进行了数据仿真测试, 得到了在不同办学规模情形下的 效益，供高职院校办学管理科学化参考。

关键词: 竞争性拨款, 高职, 办学规模, 效益, 定量研究, 数学模型

\section{1. 前言}

随着职业教育发展进入快车道, 高职院校办学规模 (包括人员与其他要素) 与效益迫切需要进行定量分析 研究, 以提高高职院校规划与发展决策的规范性、科学 性。由于高职院校实行竞争性拨款, 为了提高效益, 保 持学校又好又快发展, 应重点加强对竞争性拨款起直接 作用的支出项目投入, 适当减少对效益增加影响程度不 明显的其他支出项目, 不同支出项目或经费额度的减少 对整体效益的影响需要定量研究, 以令人信服。学校招 生产生的生均拨款是竞争性拨款中的重要部分, 但招生 规模受学校容纳量、管理难度、生师比等限制因素而不 可能无限增长, 职工规模受政策影响也有一定的控制范 围, 这时需要定量研究能适应环境变化的合适学生数与 职工数。为解决以上问题, 本文将研究建立竞争性拨款 背景下、受现有办学条件限制的适应环境变化的满足办 学规模合理与效益最大化的数学模型, 通过定量计算与 灵敏度分析, 为高职院校规划与发展提供决策管理科学
化参考。

\section{2. 国内外研究现状分析}

国内外关于办学规模与经济效益的研究有很多, 以 定性研究为主, 运用定量研究方法的实证研究较少, 部 分运用定量研究方法的研究人员采用的是运用定性与 定量相结合、重点突出定量研究、建立相关模型, 从新 的角度研究办学规模与办学效益的关系, 从而使研究方 法更为科学、研究结果更具说服力。经查阅文献, 该研 究领域以往的成果主要包括研究如何确定高校合理办 学规模、如何计量高等教育培养成本以及如何在高等教 育受益者之间合理分担教育成本等问题, 研究主要对象 是普通本科院校, 其中部分著作通过对近 10 多年历史 数据的整理、计算、分析、验证得出高校生均培养成本 与办学规模之间的关系为分段非线性二次回归模型, 并 建议地方政府在制定高校发展规划时应指导各高校确 定阶段性的办学规模, 在理清高校生均培养成本核算范 
围和规则的同时区别高校办学水平、专业差异, 制定弹 性的高校收费标准, 在划拨高校财政教育经费时应改变 目前基数加增长的拨款方式, 采用按成本分担原则和配 比比例确定拨款标准的生均拨款方式, 从而提高政府对 高校投入的公平性，高校应根据自身贷款进度和资金使 用情况, 制定财务分析指标体系, 以防范高校债务风险 给学校正常教学科研带来影响。

以上主要是普通本科院校开展的办学规模与经济 效益方面的研究工作, 经查阅文献, 在高职院校方面, 少数高职院校的研究人员对高职院校办学成本与办学 效益问题进行了研究，阐述了高职院校办学成本及其构 成、办学效益及其内涵, 分析了办学成本与办学效益的 关系, 提出了高职院校成本核算体系基本设计框架要求, 论述了高职院校加强成本核算管理提高办学效益的主 要途径: 建立健全成本核算体系, 加强成本控制与管理, 倡导节约型校园建设, 建立效益评价体系, 推广目标经 济责任制。

\section{3. 模型的建立与求解}

首先, 进行建模的准备工作, 组建团队, 成员由高 职院校领导、人事部门、财务部门、数学应用研究人员 构成, 以满足研究所涉及的部门和人员基本需要, 并通 过相关部门调阅学校数据, 进行数据分析。

\section{1. 预算基础数据分析归类}

本文通过对假设的某高职院校某年预算每项基础 数据进行分析归类，得到以下类别的分析数据:

1. 收入来源

（1）基础性生均拨款;

（2）竞争性生均拨款;

(3) 主管单位教育专项拨款; 学费、住宿费收入。

2. 支出项目

（1）人员经费人均支出;

（2）运行经费中与职工数相关的支出;

(3) 运行费中与学生数相关的支出;

(4) 人员经费固定支出;

（5）运行经费固定支出;

(6) 临时项目开支。

\section{2. 基础数据处理}

通过对某年预算的每项基础数据进行分析归类，假 设得到以下内容的分析数据。

$$
\text { （一）收入 }
$$

1. 基础性生均拨款

生均与在校学生数相关。

2. 竞争性生均拨款

包括质量提升专项、技能竞赛等。

3. 主管单位教育专项拨款
4. 学费、住宿费收入

生均与在校学生数相关。

(二) 支出

1. 人员经费人均支出

假设绩效水平，将其他自招人员、外聘教师等人员 经费折合到在编人员费用中，得到人均支出。

2. 假设运行经费中与职工数相关的支出

(1) 差旅费。

（2）办公用品、耗材、设备、邮电。

(3) 工会上缴会费。

（4）校区支出（包括办公、邮电、差旅、维修、水 电, 其中部分计入固定支出、部分与职工数相关、部分 计入临时项目支出、部分与学生数相关)。

(5) 培训费 (包括固定支出、与职工数相关的支出)。

（6）公开招聘费用。

（7）在职职工体检费用。

（8）其他印刷、耗材、培训、活动、维护费用。

（9）校企合作培训费用。

按在编职工数平均计算, 可得到人均支出。

3. 运行费中与学生数相关的支出

(1) 保安费 (部分计入固定支出、部分与学生数相 关)。

（2）校园维修（部分计入固定支出, 部分计入临时 项目支出，部分与职工数相关，部分与学生数相关)。

(3) 水电 (部分计入固定支出、部分与职工数相关、 部分与学生数相关)。

(4) 物业管理费（部分计入固定支出, 部分与学生 数相关)

（5）后勤工作经费（部分计入固定支出, 部分与学 生数相关)。

(6) 运行管理经费（部分计入固定支出, 部分与学 生数相关)。

（7）其他费用。

按现有学生数平均计算, 可得生均支出。

4. 人员经费固定支出

5. 运行经费固定支出

6. 临时项目开支

（1）运行经费临时项目开支。

(2) 人员经费临时项目开支。

7. 不可预见支出

8. 教育专项支出（教学设备购置）

\section{3. 净收益最大化模型}

假定在校学生总数为 $\mathrm{X}$, 在编职工总数为 $\mathrm{Y}$, 根据 基础数据分析结果可知（假设数据如下):

1. 年总收入为:

$(0.81+0.6) \quad \mathrm{X}+2000+2000$

即 $1.41 X+4000$

2. 年总支出为:

$0.168 \mathrm{X}+(24.83+1.81) \mathrm{Y}+751+1800+3036+350+2000$

即 $0.168 \mathrm{X}+26.64 \mathrm{Y}+7937$ 
3. 全年净收益为:

$1.41 \mathrm{X}+4000-(0.168 \mathrm{X}+26.64 \mathrm{Y}+7937)$

即 $1.242 \mathrm{X}-26.64 \mathrm{Y}-1937$

设定目标为 “净收益最大化”, 并设定限制条件, 包 括:

（1）生师比不超过 24:1;

(2) 学生总数不低于 12787 人;

(3) 职工总数不低于 500 、不超过 585 .

因此模型为基于上述限制条件的净收益最大化模 型, 观察发现其为线性规划模型, 根据两种方式分析求 解 (线性规划模型的经典图解法、WPS 表格软件的线性 规划模型经典单纯形解法运算功能), 得到如下结果:

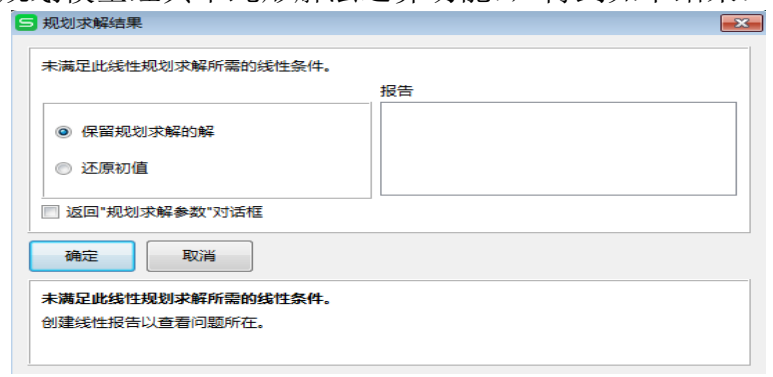

图 1 WPS 线性规划功能运行情况

图 1 结果显示, 在现有数据和生师比 (24:1) 情形 下，未达到盈亏平衡。

对 WPS 表格数据的线性规划表分析得到结果显示, 在现有数据和生师比情形下, 未达到盈亏平衡, 初步计 算结果为亏损 441 万元。

\section{4. 灵敏度分析}

如下表, 分别进行 4 个维度的灵敏度测试: 测试一：只增加学生数, 职工数固定不变。 测试二: 扩大规模, 生师比不变, 同时增加学生数 和职工数。

测试三：增加竞争性拨款，保持规模不变。

测试四: 减少运行经费中的人均支出和生均支出。

\section{表 1 灵敏度分析表}

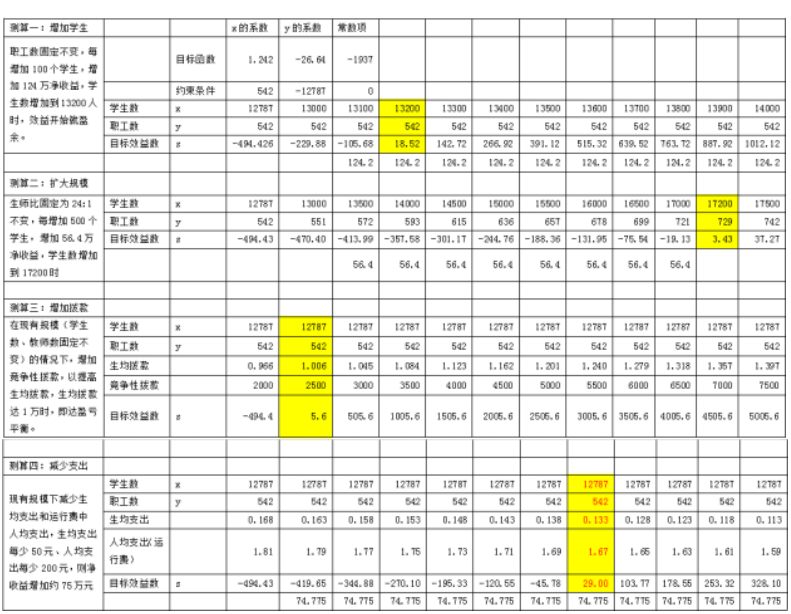

\section{5. 结论}

根据上述分析，形成如下结论：

1. 在假设数据和生师比情形下, 未达到盈亏平衡, 仿真计算结果为亏损 494 万元。

2. 在数据不变的情形下, 每增加 100 个学生, 增加 124 万元净收益, 学生总数达到 13200 人时, 开始有盈 余。

3. 保持生师比, 扩大办学规模, 同时增加学生数和 职工数, 每增加 500 个学生, 增加 56.4 万元净收益, 学生数达到 17200 人时, 开始有盈余。

4. 通过竞争, 取得更高生均拨款系数, 能够显著改 善效益问题, 生均拨款达 1 万元时, 即可达到盈亏平衡。

5. 减少运行支出, 将生均支出和人均 (职工) 支出 由 0.168 和 1.81 分别降到 0.133 和 1.67 , 即有盈余。

\section{6 . 建议}

根据上述结论, 给出如下建议:

1. 建议加强重点攻关, 对可增加竞争性生均拨款 的项目积极申报, 积极参加技能比赛并争取获奖; 同时 增大校办产业创收力度, 以 “将蛋糕做大”。

2. 建议减少 “回报效益不明显” 的支出, 如 “非必 须” 的差旅费，还可适当收缩协会、行业及其他机构的 比赛 (收缩的经费集中加强直接影响生均拨款的项目和 比赛), 但应注意是适当逐步收缩, 避免改革力度过大过 快导致人心不稳。

3. 扩大招生规模。

4. 适度招聘新职工。

5. 多措并举

单纯使用扩充职工数和学生数的方式难以解决盈 亏不平衡问题, 因此, 建议多措并举, 将减项（精简支 出项目)、树核（重点攻关有拨款的项目）、扩招（扩充 招生和职工数)、提质 (提高发展质量提升财政拨款系 数)、开拓 (扩充新的经济收入增长点) 同时进行, 同步 
发力, 尤其是加大力量提高生均拨款系数, 以求办学经 济效益更明显。

\section{4. 研究展望}

竞争性拨款项目还有多种, 有待厘清, 拟通过研究 相关政策和联系相关部门作深入研究。另外, 本文只以 假设的某年数据进行了仿真测试, 后续将研究假设的多 年数据进行综合分析与预测。

\section{项目基金}

本文为湖北交通职业技术学院重点项目 《竞争性拨款背景下高职办学规模与效益的 定量研究》(Z2019002) 的阶段性成果之一。

\section{REFERENCES}

[1] Qin C. (2011). Comprehensive evaluation on scale benefit of Higher Vocational Colleges. J. of Xuzhou Normal Uni. (Philosophy and Social Sciences Edition), 37: $138-141$.

[2] Hua J.C. (2012). The scale and benefit of running a multi campus university. J. of Xuzhou Normal Uni. (Philosophy and Social Sciences Edition), 9: 18-22.

[3] Qin C. (2011). The conclusion analysis and Development Countermeasures of Jiangsu Higher Vocational College scale benefit research. MEITAN HIGHER EDUCATION, 6: 19-23.

[4] You C.M. (2011). Research on the model of relationship between school running scale and school running benefit of newly built Universities. J. of Xuzhou Normal Uni. (Philosophy and Social Sciences Edition), 6: 128-129.

[5] Ren Z.Y. (2017). Analysis on the difficulties and Countermeasures of the implementation of per student funding system in Higher Vocational Education. http://www.moe.gov.cn/s78/A07/zcs_ztzl/ztzl_zcs1518/zcs 1518_zcjd/201708/t20170824_311849.html. 